\title{
First Line Medical Support: Sorting it Out.
}

In recent years, there has been growing dissent within the $\operatorname{ranks}(1,2)$ about a medical doctrine that appeared to be stuck in the days of the Cold War. Indeed, there may have been some justification, as Medical Support in the Field, which was produced in the early 1980s, remains the backbone of authorised medical doctrine. Since those days however, the nature of warfare has changed, medical treatments have advanced and our soldiers and their families have higher expectations of survival after injury. These concerns were given official recognition last year when DGAMS was tasked with leading the review (reform) of Role 1 medical doctrine. The aim of this editorial is to rekindle the debate about prehospital medical doctrine and to outline where we currently stand.

But first of all, why does it appear that we have made little progress to date? Those with good memories will remember that Military Doctrine is defined as the "formal expression of military knowledge and thought, that the Army accepts as being relevant at a given time" (emphasis added)(3). It is the Commanding Officer of a unit who has ownership of Role 1 medical assets and who, with advice from his RMO, is responsible for ensuring that his unit has adequate medical support(4). Therefore, it is the Arms and Service Directors who must be persuaded when it comes to changing Role 1 doctrine. That is not to say that they have not listened to medical advice, in fact the contrary is the case. In the past, our problem has been the old adage that any 3 doctors will have 4 opinions between them. We have not, to date, presented the Arms and Service Directors with a unified, agreed solution. As the Chief of Staff said in the last issue "[doctrine] has not been developed and staffed so that it can be dismissed as either an irrelevance, or worse still, an attempt to control and confine practice. Rather it requires us all to use it intelligently and carefully in our military practice"(5).

So where are we at present? The impending publication of Army Doctrine Publication, Volume 3 Logistics (Medical Supplement) outlines the principles by which health care and medical support should be provided to the British Army. These principles have been agreed by the Army as a whole and formed the basis of the first line planning yardsticks recently published in the British Army Review - for army wide coverage(6). In brief, two key factors were identified that affected the development of medical doctrine. The first was the requirement to provide standards of care that were comparable to those available in peace, within the constraints of conditions on the battlefield. The second was the importance of providing medical care as directed by clinical need rather than operational expediency - i.e. a capability based approach. This is not to say that medical support may ignore the operational environment, just that our emphasis should be more on saving lives rather than simply reducing logistic drag.

One of the major advances made when the Medical Supplement was released was that it marked the UK acceptance of the 12-4 hour rule(7). The army as a whole accepted that skilled resuscitation should be provided within the first hour of wounding. That, for the most severely wounded, damage control surgery (previously known as surgical resuscitation) should be provided within 2 hours of wounding and that primary surgery should be provided within 4 hours for those with severe head injuries and within 6 hours for all others who required it. Thus, we now have agreed planning timelines upon which we can hang our arguments for reform.

Finally, when thinking about the present one must not forget the future, as it is against this vision that we must structure today's force. Tactical doctrine describes how we do our business today whilst force development determines which capabilities will be required in the future. The nature of equipment procurement is such that force development must look 10, or even 20, years into the future. So where could we be heading? Last month, the Royal College of Surgeons of England and the British Orthopaedic Association together published a report(8) that is likely to influence the provision of civilian trauma care for many years to come. Admittedly, civilian trauma and the civilian environment are very different to their military counterparts. However, they made recommendations that will influence the way we operate.

In particular, is the Role 1 / 2 capability split sacrosanct, or should pre-hospital medical care be fully integrated? What is the correct balance between active medical 
intervention and rapid evacuation? Indeed, must every casualty be evacuated to the Regimental Aid Post, or should the severely wounded be evacuated direct to a trauma team? Where should medical facilities be located, in an asymmetric war would a surgical team really be safer in the rear of the Brigade area? What novel interventions and concepts are being developed that we could adopt, could trauma victims be placed in suspended animation(9) or will other seemingly bizarre techniques emerge? These are just some of the questions that need to be considered when identifying what capabilities military medics will require in the decades to come.

In conclusion, no single individual has the answers to all these questions, but we as an organisation probably do. As the development of Role 1 medical doctrine enters a new, exciting phase I would like to end this editorial with an invitation to those with an interest to enter the debate. As always, the staffing process begins with bright ideas being passed up through the chain of command. However, in this case I would ask that information copies be sent to the Medical Branch at Headquarters Land Command and the Army Medical Directorate. These ideas will inform the development of a series of papers that will be circulated for comment before a final paper is presented for formal approval and a new doctrine accepted. We are in an excellent position to bring military pre-hospital trauma care into the 21 st century and it is essential that we grasp the opportunity with both hands.

\section{References}

1. Bricknell MC, 'First Line Medical Support - the Need for an Integrated Package', British Army Review, 1991; 98, 53-59

2. Lynch P, 'First Line Medical Support: Time it was Sorted Out', British Army Review, 1996; 114, 5558

3. Ministry of Defence, British Military Doctrine, London, HMSO, 1996, p 1-1.

4. Ministry of Defence, Queen's Regulations for the Army - 1975, London, HMSO, 1996, Para 5.321.

5. Hawley A, 'Doctrine, Dogma and Debate', $f R$ Army Med Corps, 2000; 146: 60-61.

6. Murray JW, 'Planning Yardsticks for the Provision of First Line Medical Support', British Army Review, 1999; 123: 57-60.

7. The 1-2-4 hour rule has been part of NATO Medical Doctrine since 1996.

8. RCS Engl and BAO, Better Care for the Severely Injured. London, Royal College of Surgeons of England and the British Orthopaedic Association, 2000.

9. Bellamy RF et al, 'Suspended Animation for Delayed Resuscitation', Crit Care Med, 1996; 24 (2): S24-47.

AG TERRELL 